\title{
Sequence-controlled $\alpha$-methylstyrene/styrene copolymers: syntheses and sequence distribution resolution
}

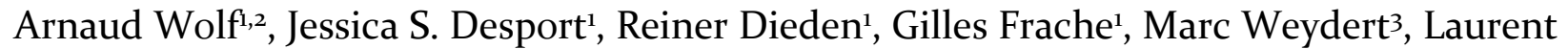

Poorters 3 , Daniel Schmidt ${ }^{1}$, Pierre Verge ${ }^{*}$

1 Luxembourg Institute of Science and Technology, L-4362 Esch-sur-Alzette, Luxembourg

2 University of Luxembourg, L-4365 Esch-sur-Alzette, Luxembourg

3 Goodyear Innovation Center Luxembourg, L-7750 Colmar-Berg, Luxembourg

Experimental section

. .1

Nuclear magnetic resonance experiments

.1

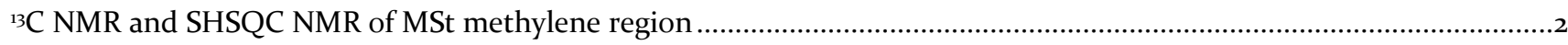

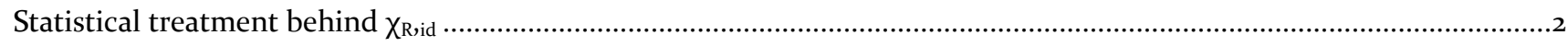

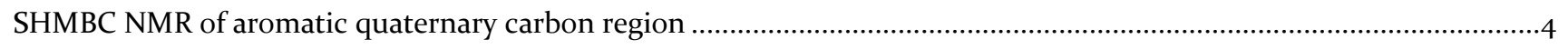

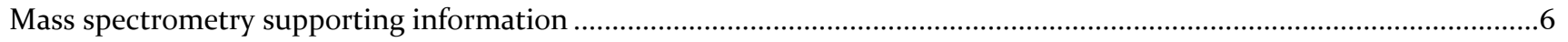

\section{Experimental section}

Nuclear magnetic resonance experiments

${ }^{1} \mathbf{H}$ NMR spectra were acquired using a 30 degree nutation pulse (Bruker sequence zg3o), $64 \mathrm{k}$ complex data points and 16 transients with a 1 s relaxation delay. Prior to transformation, the data was zero-filled once and apodized with a $0.3 \mathrm{~Hz}$ exponential window function.

${ }^{13}$ C NMR spectra were acquired using an inverse-gated decoupling scheme with a zo degree nutation pulse (Bruker sequence zgig3o), 64k complex data points and 2048 transients with a 6 s relaxation delay (the longest longitudinal relaxation time $\mathrm{T}_{1}$ had been previously determined on sample poly(MSt-alt-St) 2 to be $\left.0.4 \mathrm{~s}\right)$. Prior to transformation, the data was apodized with a $3 \mathrm{~Hz}$ exponential window function.

COSY spectra were acquired as 128 increments using gradient selection and purge pulses (Bruker sequence cosygpppqf). The F1-data was zero-filled to $1 \mathrm{k}$ data points and a sine window function applied.

For HSQC spectra, 256 increments of 8 transients each were acquired using Echo-AntiEcho quadrature phase detection (Bruker sequence hsqcedetgpsisp2.3). The data was zero-filled up to $\mathrm{kk}$ data points in the F1-dimension and a squaredcosine window function was applied before Fourier transform. 
HMBC spectra were acquired using 8 transients for 128 increments (Bruker sequence hmbcgplpndqf). The F1-dimension was zero-filled up to $\mathrm{k}$ data points and a sine-bell window function was applied prior to Fourier transform.

In the case of selective HSQC (SHSQC, Bruker sequence shsqcetgpsisp2.2) and selective HMBC (SHMBC, Bruker sequence shmbcctetgpl2nd) 128 increments of 8 transients each were acquired in Echo-Antiecho mode (Bruker sequence shsqcetgpsisp2.2). In order to select the F1-range, the offset (oip) and sweep-width (SW1) were set accordingly. Prior to transformation, the data was zero-filled up to $1 \mathrm{k}$ data points in F1 and the data was apodized (square-cosine-bell for SHSQC while for SHMBC a mixed sine/cosine function $(\mathrm{ssb}=4)$ in $\mathrm{F}_{2}$ and a square-cosine function in F1 were employed.

\section{C NMR and SHSQC NMR of MSt methylene region}

Figure $\mathrm{S} 1(\mathrm{a})$ illustrates the impact of different monomer sequences in poly(MSt-co-St) on the methylene group ${ }^{13} \mathrm{C}$ NMR chemical shifts. In our case, poly(MSt) revealed one major contribution between 23.6 and 24.7 ppm, corresponding to the contribution of multiple MSt repeating units. This was confirmed by the presence of the same contribution in poly(MStblock-St). On the contrary, poly(MSt-random-St) and poly(MSt-alt-St) revealed another contribution from 22.6 to $23.7 \mathrm{ppm}$. This region was defined as a mixed region where diads and/or triads of alternating MSt and St units are present. Selective heteronuclear single quantum coherence NMR (SHSQC NMR) was performed on poly(MSt-random-St) and revealed that the signal between 22.6 and 24.7 ppm was composed of multiple overlapping cross-peaks that make the quantification of individual diads (or triads) rather difficult in this region (Figure $\mathrm{S}_{1}(\mathrm{~b})$ ). Due to these observations, the region of aromatic quaternary carbons was investigated.
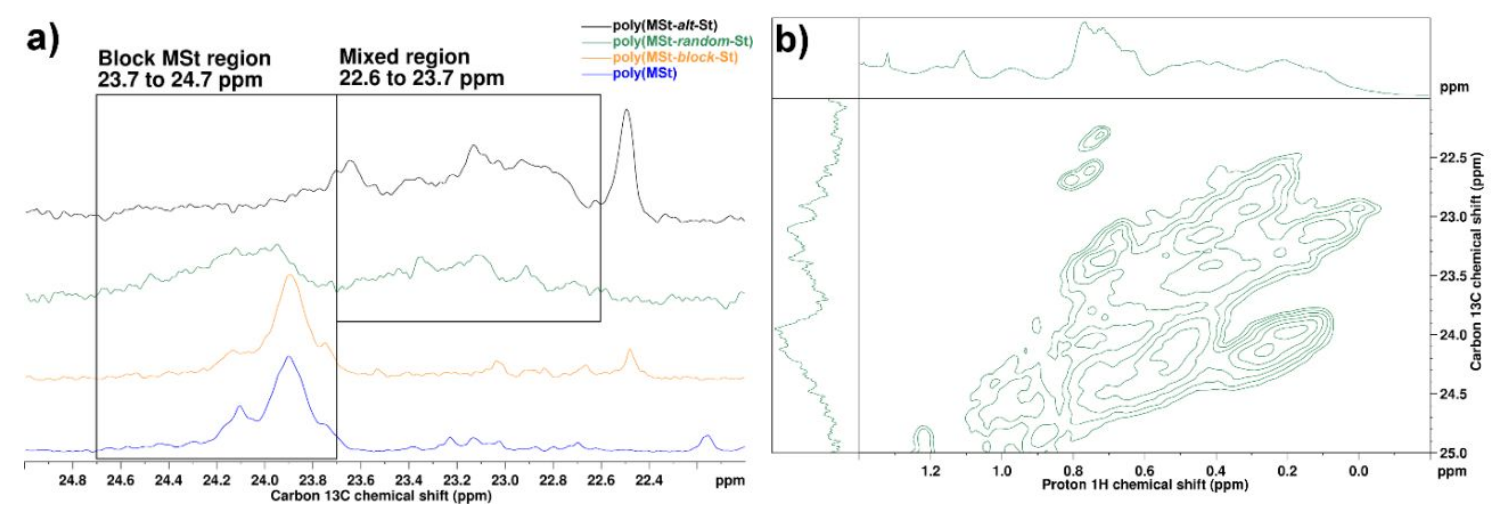

Figure S1: a) ${ }^{13}$ C NMR of the methylene region for poly(MSt-alt-St) 1 (black), poly(MSt-random-St) (green), poly(MSt-block-St) (orange) and a poly(MSt) standard (blue). b) SHSQC NMR of the methylene region for poly(MSt-random-St).

\section{Statistical treatment behind $\chi_{\text {Rzid }}$}

The sequence distribution of a copolymer can be assessed by calculating the value of $\chi_{R, \exp }$ using Equation 5 (main text).

Theoretically, for infinitely long copolymer chains containing a 1:1 co-monomer ratio, this coefficient can vary between $\chi_{\mathrm{R}, \mathrm{id}}$ $=\mathrm{o}$ (for ideal block copolymers) to $\chi_{\mathrm{R}, \mathrm{id}}=\mathbf{2}$ (for ideal alternating copolymers). In our case, however, the copolymer compositions deviate somewhat from a 1:1 co-monomer ratio and the molecular weight is rather low (<50oo g/mol). 
Statistically, the value of $\chi_{R, \text { id }}$ will be impacted most strongly by the molecular weight in the case of a block copolymer, and by deviations in composition in the case of an alternating copolymer. Accounting for these effects, corrected $\chi_{\mathrm{R}, \text { id }}$ values may be calculated for the targeted copolymer architecture.

In the case of a perfect block copolymer, there is only a single mixed (\{MS $\},\{\mathrm{SM}\}$ ) diad diluted by an infinite number of homopolymer diads ( $\{\mathrm{MM}\},\{\mathrm{SS}\})$, meaning $\mathrm{P}_{2}\{\mathrm{MS}\}=\mathrm{P}_{2}\{\mathrm{SM}\}$ is infinitely small (zero for the purposes of our calculations). For an ideal block copolymer with a finite $\mathrm{DP}_{\mathrm{n}}$, on the other hand, we expect to find a single mixed diad among the $\left(\mathrm{DP}_{\mathrm{n}}-\right.$ 1) diads present, meaning $P_{2}\{M S\}=P_{2}\{S M\}=1 /\left(D P_{n}-1\right)$. Thus, the expression for $\chi_{R}$ (equation 5 , main text) may be rewritten to find the smallest possible value for a given molecular weight $\left(\chi_{R, \min }\right)$ as follows:

$\chi_{R, \min }=\left(1 /\left(D P_{n}-1\right)\right) /\left(P_{1}\{M\} * P_{1}\{S\}\right)$

As an example, this is applied to the $3780 \mathrm{~g} / \mathrm{mol}$ poly(MSt-block-St) copolymer (44:56, MSt/St co-monomer composition, $\left.\mathrm{DP}_{\mathrm{n}} \sim 34\right)$ as follows:

$\chi_{R, \min }=(1 / 33) /(0.44 * 0.56)=0.12$

What this calculation shows is that the lowest possible value $\chi_{R}$ may take for this particular copolymer, assuming an ideal block copolymer structure, is o.12, not zero. Thus, for block-copolymers, the $\chi_{R, \exp }$ coefficient should be compared to a $\chi_{R, i d}$ value derived from these calculations.

By the same statistical approach, it is clear that a value of $\chi_{R}=2$ is only achievable when the co-monomer composition is exactly 1:1. In practice, when the composition deviates from this idealized stoichiometry, the maximum achievable value of $\chi_{R}$ will be lower. An easy way to assess this value $\left(\chi_{R, \max }\right)$ for alternating copolymers with non-ideal compositions begins with a restatement of Equations 2 and 3 (main text):

$P_{1}\{M\}=P_{2}\{M M\}+P_{2}\{M S\}$

$P_{1}\{S\}=P_{2}\{S S\}+P_{2}\{M S\}$

In this example we consider a copolymer that is MSt rich. If such a copolymer displays the maximum possible alternating tendency, it should be impossible to find two styrene units next to each other (that is, $\mathrm{P}_{2}\{\mathrm{SS}\}=0$ ). Therefore:

$P_{1}\{S\}=0+P_{2}\{M S\}=P_{2}\{M S\}$

The expression for $\chi$ (equation 5 , main text) may then be rewritten to find $\chi_{R, \max }$ as follows:

$$
\begin{aligned}
\chi_{R, \max } & =P_{2}\{M S\} /\left(P_{1}\{M\} * P_{1}\{S\}\right) \\
& =P_{1}\{S\} /\left(P_{1}\{M\} * P_{1}\{S\}\right) \\
& =1 / P_{1}\{M\}
\end{aligned}
$$

The same treat is equally applicable in the case of St rich copolymers, in which the above approach yields the following: $\chi_{R, \max }=1 / P_{1}\{S\}$

The general expression is: 
$\chi_{R, \max }=1 / P_{1}\left\{M_{\text {major }}\right\}$

...where $\mathrm{M}_{\text {major }}$ represents the monomer that comprises the majority of the copolymer. Considering poly(MSt-alt-St) 1 , for example, the composition is $53 \% \mathrm{MSt}$, and $47 \%$ St. In this case, the maximum value of $\chi_{\mathrm{R}}$ this copolymer could have would be 1.90 instead of 2 .

Based on the considerations described above, $\chi_{R, \text { id }}$ has been calculated for each copolymer and is presented in Table 2 (main text). Note that the value of $\chi_{\mathrm{R}, \mathrm{id}}$ for a random copolymer is considered to be unaffected by the aforementioned concerns and is therefore given as 1.

\section{$\underline{\text { SHMBC NMR of aromatic quaternary carbon region }}$}

The diads' ranges ( $\{\mathrm{MM}\},\{\mathrm{SS}\},\{\mathrm{MS}\}$ and $\{\mathrm{SM}\}$ ) were determined thanks to ${ }^{1} \mathrm{D}^{13} \mathrm{C}$ NMR and selective heteronuclear multiple bond correlation NMR in the region of aromatic quaternary carbons and methylene protons (Figure S2).

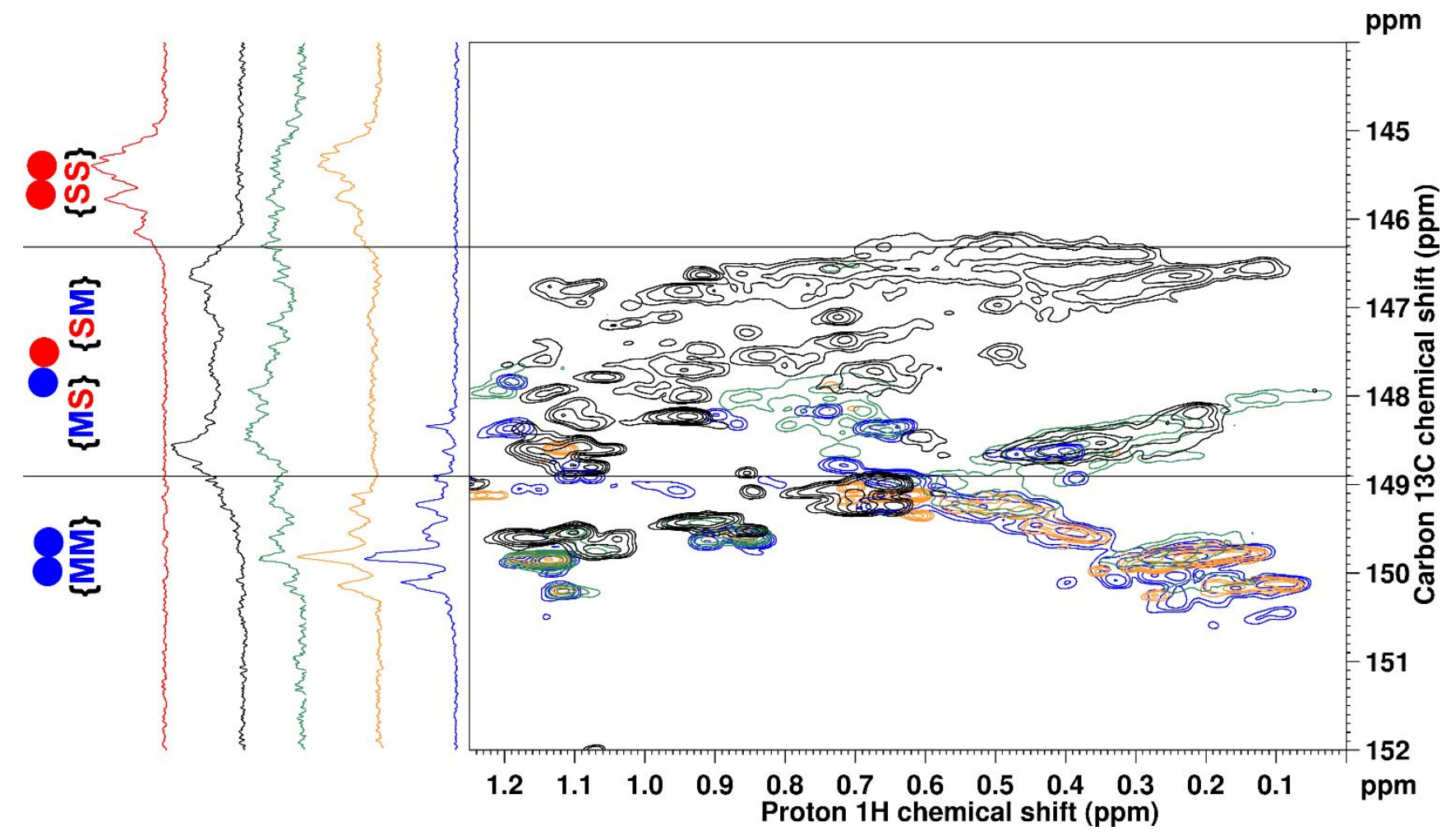

Figure S2: SHMBC in the region of cross-peaks between aromatic quaternary carbons and methyl groups of MSt. Evaluations of the $\{\mathrm{MM}\},\{\mathrm{SS}\}$ and mixed ( $\{\mathrm{MS}\}$ and $\{\mathrm{SM}\})$ diad regions are shown, and color codes from the main text are respected: red for poly(St) standard, black for poly(MSt-alt-St) 1, green for poly(MSt-random-St), orange for poly(MSt-block-St) and blue for poly(MSt) standard. Data acquired in $\mathrm{CDCl}_{3}$ at $600 \mathrm{MHz}$.

The regions in Figure S2 were defined in order to avoid as much as possible any over- or under-estimation of the integral results due to peak overlap. However, we are conscious that the poly(MSt) signal can extend below 148.9 ppm, mainly due to the tacticity of the polymer. This means that $P_{2}\{M S\}+P_{2}\{S M\}$ is certainly overestimated at the expense of $P_{2}\{M M\}$. Another small overlap was detected between the $\{\mathrm{SS}\}$ and mixed regions. The impact of these overlapping contributions was investigated in terms of over- and/or under-estimation of each range. The overall estimations are described below: 
- $\quad$ Overestimation of $\mathrm{P}_{2}\{\mathrm{MS}\}+\mathrm{P}_{2}\{\mathrm{SM}\}$ by $14 \%$ of $\mathrm{P}_{2}\{\mathrm{MM}\}$ at the expense of $\mathrm{P}_{2}\{\mathrm{MM}\}$

- $\quad$ Overestimation of $\mathrm{P}_{2}\{\mathrm{MS}\}+\mathrm{P}_{2}\{\mathrm{SM}\}$ by $4.5 \%$ of $\mathrm{P}_{2}\{\mathrm{SS}\}$ at the expense of $\mathrm{P}_{2}\{\mathrm{SS}\}$

- $\quad$ Overestimation of $\mathrm{P}_{2}\{\mathrm{SS}\}$ by $2.5 \%$ of $\mathrm{P}_{2}\{\mathrm{MS}\}+\mathrm{P}_{2}\{\mathrm{SM}\}$ at the expense of $\mathrm{P}_{2}\{\mathrm{MS}\}+\mathrm{P}_{2}\{\mathrm{SM}\}$

These estimations were calculated assuming the regions associated with the diads of interest remained fixed in size and location independent of the copolymer structure. These corrections yielded $\chi_{R, \exp }$ values within \pm o.o1 of those reported in Table 2 (main text), indicating that such effects are minor and may be safely disregarded.

Table S1: ${ }^{13} C$ NMR integration results and calculations of $P_{1}\{M\}, P_{1}\{S\}$ and $\chi_{R}$ taking into account the corrections due to overlapping peaks.

\begin{tabular}{|c|c|c|c|c|c|c|c|}
\hline References & $\mathrm{P}_{2}\{\mathrm{MM}\}(\%)$ & ${ }_{2} \mathrm{P}_{2}\{\mathrm{MS}\}(\%)$ & $\mathrm{P}_{2}\{\mathrm{SS}\}(\%)$ & $\mathrm{P}_{1}\{\mathrm{M}\}(\%)$ & $\mathrm{P}_{1}\{\mathrm{~S}\}(\%)$ & $\chi_{\mathrm{R}, \mathrm{id}}$ & $\chi_{R, \exp }$ \\
\hline Poly(MSt-alt-St) 1 & 14 & 81 & 5 & 54 & 46 & 1.84 & 1.64 \\
\hline Poly(MSt-alt-St) 2 & 13 & 82 & 5 & 54 & 46 & 1.86 & 1.64 \\
\hline Poly(MSt-alt-St) 3 & 14 & 79 & 7 & 53 & 47 & 1.88 & 1.58 \\
\hline Poly(MSt-alt-St) 4 & 11 & 72 & 17 & 47 & 53 & 1.90 & 1.45 \\
\hline Poly(MSt-alt-St) 5 & 15 & 80 & 5 & 55 & 45 & 1.83 & 1.61 \\
\hline Poly(MSt-alt-St) 6 & 10 & 75 & 15 & 48 & 52 & 1.91 & 1.51 \\
\hline Poly(MSt-alt-St) 7 & 10 & 80 & 10 & 50 & 50 & 1.99 & 1.59 \\
\hline Poly(MSt-block-St) & 41 & 10 & 49 & 46 & 54 & 0.12 & 0.20 \\
\hline Poly(MSt-random-St) & 23 & $5^{2}$ & 25 & 48 & 52 & 1.00 & 1.04 \\
\hline
\end{tabular}


Table S2: Molecular assignment of fragments obtained by CID (at $\mathrm{E}_{\text {lab }}=40$ ) of poly(MSt-alt-St) from precursor ion $\left[\mathrm{C}_{4} \mathrm{H}_{9}-\left(\mathrm{C}_{8} \mathrm{H}_{8}\right)_{6}\left(\mathrm{C}_{9} \mathrm{H}_{10}\right)_{7}-\mathrm{H}+\mathrm{Ag}\right]^{+}$with $\mathrm{m} / \mathrm{z}=1615 \cdot 91$. Description of the fragments labeled on Figure 5 and additional peaks.

\begin{tabular}{|c|c|c|c|c|c|}
\hline \multicolumn{2}{|c|}{ Fragment } & Molecular formula & Theoretical $\mathrm{m} / \mathrm{z}$ & Experimental $\mathrm{m} / \mathrm{z}$ & $\Delta \mathrm{ppm}$ \\
\hline $\mathrm{y} 4$ & & $\mathrm{C}_{34} \mathrm{H}_{3} 6 \mathrm{Ag}+1$ & 551.1862 & 551.1891 & $5 \cdot 3$ \\
\hline $\mathrm{y}_{5 \mathrm{C}}$ & & $\mathrm{C}_{37} \mathrm{H}_{42} \mathrm{Ag}+1$ & 593.2332 & - & - \\
\hline y5a & $\mathrm{z} 5$ & $\mathrm{C}_{42} \mathrm{H}_{44} \mathrm{Ag}+1$ & 655.2488 & 655.2506 & 2.7 \\
\hline $\mathrm{y} 5 \mathrm{~b}$ & & $\mathrm{C}_{43} \mathrm{H}_{4} 6 \mathrm{Ag}+1$ & 669.2645 & 669.2664 & 2.8 \\
\hline y6 & & $\mathrm{C}_{51} \mathrm{H}_{54} \mathrm{Ag}+1$ & $773 \cdot 3271$ & $773 \cdot 3270$ & -0.1 \\
\hline $\mathrm{y} 7 \mathrm{c}$ & & $\mathrm{C}_{54 \mathrm{H} 6 \mathrm{oAg}+1}$ & $815 \cdot 3741$ & $815 \cdot 3750$ & 1.2 \\
\hline y7a & $\mathrm{z} 7$ & $\mathrm{C}_{59} \mathrm{H} 62 \mathrm{Ag}+1$ & $877 \cdot 3897$ & $877 \cdot 3884$ & -1.5 \\
\hline $\mathrm{y} 7 \mathrm{~b}$ & & $\mathrm{C} 60 \mathrm{H} 64 \mathrm{Ag}+1$ & 891.4054 & 891.4052 & -0.2 \\
\hline y8 & & $\mathrm{C} 68 \mathrm{H}_{72} \mathrm{Ag}+1$ & 995.4679 & 995.4653 & -2.7 \\
\hline y9c & & $\mathrm{C}_{71} \mathrm{H}_{78 \mathrm{Ag}+1}$ & $1037 \cdot 5149$ & 1037.5149 & 0.0 \\
\hline y9a & z9 & $\mathrm{C}_{7} 6 \mathrm{H} 8 \mathrm{oAg}+1$ & 1099.5305 & $1099 \cdot 5271$ & -3.1 \\
\hline ygb & & $\mathrm{C}_{77} \mathrm{H} 82 \mathrm{Ag}+1$ & 1113.5462 & $1113 \cdot 5428$ & -3.1 \\
\hline y10 & & $\mathrm{C}_{85} \mathrm{H}_{90 \mathrm{Og}+1}$ & 1217.6088 & 1217.6034 & $-4 \cdot 4$ \\
\hline y11c & & $\mathrm{C} 88 \mathrm{H}_{96} \mathrm{Ag}+1$ & 1259.6558 & 1259.6525 & -2.6 \\
\hline y11a & $\mathrm{Z11}$ & $\mathrm{C}_{93} \mathrm{H}_{98} \mathrm{Ag}+1$ & 1321.6714 & 1321.6648 & -5.0 \\
\hline y11b & & $\mathrm{C}_{94 \mathrm{H} 100 \mathrm{Ag}+1}$ & 1335.6871 & - & - \\
\hline y12 & & $\mathrm{C}_{102 \mathrm{H}} \mathrm{H} 8 \mathrm{Ag}+1$ & 1439.7497 & 1439.7404 & -6.4 \\
\hline a5 & & $\mathrm{C}_{39} \mathrm{H}_{4} 6 \mathrm{Ag}+1$ & 621.2645 & 621.2667 & 3.5 \\
\hline a6c & & $\mathrm{C}_{42} \mathrm{H}_{52} \mathrm{Ag}+1$ & 663.3115 & - & - \\
\hline a6a & $\mathrm{b}_{5}$ & $\mathrm{C}_{47} \mathrm{H}_{54} \mathrm{Ag}+1$ & $725 \cdot 3271$ & $725 \cdot 3289$ & 2.5 \\
\hline $\mathrm{a} 6 \mathrm{~b}$ & & $\mathrm{C}_{4} 8 \mathrm{H}_{5} 6 \mathrm{Ag}+1$ & $739 \cdot 3428$ & $739 \cdot 3440$ & 1.7 \\
\hline $\mathrm{a} 7$ & & $\mathrm{C}_{5} 6 \mathrm{H}_{6}{ }_{5} \mathrm{Ag}+1$ & 843.4054 & 843.4045 & -1.0 \\
\hline a8c & & $\mathrm{C}_{59} \mathrm{H}_{70 \mathrm{Og}+1}$ & 885.4523 & 885.4525 & 0.2 \\
\hline a8a & b7 & $\mathrm{C}_{64} \mathrm{H}_{72} \mathrm{Ag}+1$ & 947.4679 & 947.4661 & -2.0 \\
\hline $\mathrm{a} 8 \mathrm{~b}$ & & $\mathrm{C}_{6} \mathrm{H}_{74} \mathrm{Ag}+1$ & 961.4836 & 961.4830 & -0.6 \\
\hline a9 & & $\mathrm{C}_{73} \mathrm{H} 82 \mathrm{Ag}+1$ & 1065.5462 & 1065.5431 & -2.9 \\
\hline a1oc & & $\mathrm{C}_{7} 6 \mathrm{H} 88 \mathrm{Ag}+1$ & 1107.5932 & $1107 \cdot 5918$ & -1.2 \\
\hline a1oa & b9 & $\mathrm{C} 81 \mathrm{H}_{90} \mathrm{Ag}+1$ & 1169.6088 & 1169.6039 & -4.2 \\
\hline a1ob & & $\mathrm{C}_{22} \mathrm{H}_{92} \mathrm{Ag}+1$ & 1183.6245 & 1183.6212 & -2.7 \\
\hline all & & $\mathrm{C}_{90 H 10 o A g+1}$ & 1287.6871 & 1287.6815 & $-4 \cdot 3$ \\
\hline $\mathrm{a} 12 \mathrm{c}$ & & $\mathrm{C}_{93} \mathrm{H} 106 \mathrm{Ag}+1$ & 1329.7340 & - & - \\
\hline a12a & b11 & $\mathrm{C}_{98 \mathrm{H}} \mathrm{Ho}_{\mathrm{Ag}+1}$ & 1391.7497 & 1391.7433 & -4.6 \\
\hline a12b & & $\mathrm{C}_{99 \mathrm{H} 110 \mathrm{Ag}+1}$ & 1405.7653 & - & - \\
\hline & & $\mathrm{C}_{55} \mathrm{H} 62 \mathrm{Ag}+1$ & $829 \cdot 3897$ & $829 \cdot 3900$ & 0.4 \\
\hline & & $\mathrm{C}_{72} \mathrm{H} 8 \mathrm{oAg}+1$ & 1051.5306 & 1051.5283 & -2.1 \\
\hline & & $\mathrm{C} 89 \mathrm{H}_{9} 8 \mathrm{Ag}+1$ & 1273.6714 & 1273.6687 & -2.1 \\
\hline & & $\mathrm{C}_{106 \mathrm{H}} 116 \mathrm{Ag}+1$ & 1495.8123 & 1495.8078 & -3.0 \\
\hline & & $\mathrm{C}_{5} \mathrm{OH}_{52} \mathrm{Ag}+1$ & $759 \cdot 3115$ & $759 \cdot 3123$ & 1.1 \\
\hline & & $\mathrm{C}_{67} \mathrm{H}_{70 \mathrm{Og}+1}$ & 981.4523 & 981.4503 & -2.0 \\
\hline & & $\mathrm{C} 84 \mathrm{H} 88 \mathrm{Ag}+1$ & 1203.5932 & 1203.5866 & -5.4 \\
\hline & & C101H106Ag+1 & 1425.7340 & $1425 \cdot 7257$ & -5.8 \\
\hline
\end{tabular}


Table S3: Molecular assignment of fragments labeled on Figure ${ }_{5}$, obtained by CID (at $\left.\mathrm{E}_{\text {lab }}=40\right)$ of poly $(\mathrm{MSt}-\mathrm{alt}$-St) from precursor ion $\left[\mathrm{C}_{4} \mathrm{H}_{9}-\left(\mathrm{C}_{8} \mathrm{H}_{8}\right)_{6}\left(\mathrm{C}_{9} \mathrm{H}_{10}\right)_{6}-\mathrm{H}+\mathrm{Ag}\right]^{+}$with $\mathrm{m} / \mathrm{z}=1497.83$.

\begin{tabular}{|c|c|c|c|c|}
\hline y3 & $\mathrm{C}_{33} \mathrm{H}_{34} \mathrm{Ag}+1$ & 433.1115 & 433.1080 & 8.1 \\
\hline$Y_{4} b$ & $\mathrm{C}_{34} \mathrm{H}_{3} 6 \mathrm{Ag}+1$ & 551.1889 & 551.1862 & 4.9 \\
\hline$Y_{5}$ & $\mathrm{C}_{42} \mathrm{H}_{44} \mathrm{Ag}+1$ & 655.2506 & 655.2488 & 2.7 \\
\hline y7 & $\mathrm{C}_{59} \mathrm{H} 62 \mathrm{Ag}+1$ & $877 \cdot 3890$ & $877 \cdot 3897$ & -0.8 \\
\hline y8a & $\mathrm{C}_{7} \mathrm{H}_{70} \mathrm{Ag}+1$ & 981.4502 & 981.4523 & -2.1 \\
\hline y8b & $\mathrm{C}_{68} \mathrm{H}_{72} \mathrm{Ag}+1$ & 995.4658 & 995.468 o & -2.2 \\
\hline y9 & $\mathrm{C}_{7} 6 \mathrm{H} 8 \mathrm{oAg}+1$ & $1099 \cdot 5270$ & 1099.5306 & -2.9 \\
\hline
\end{tabular}




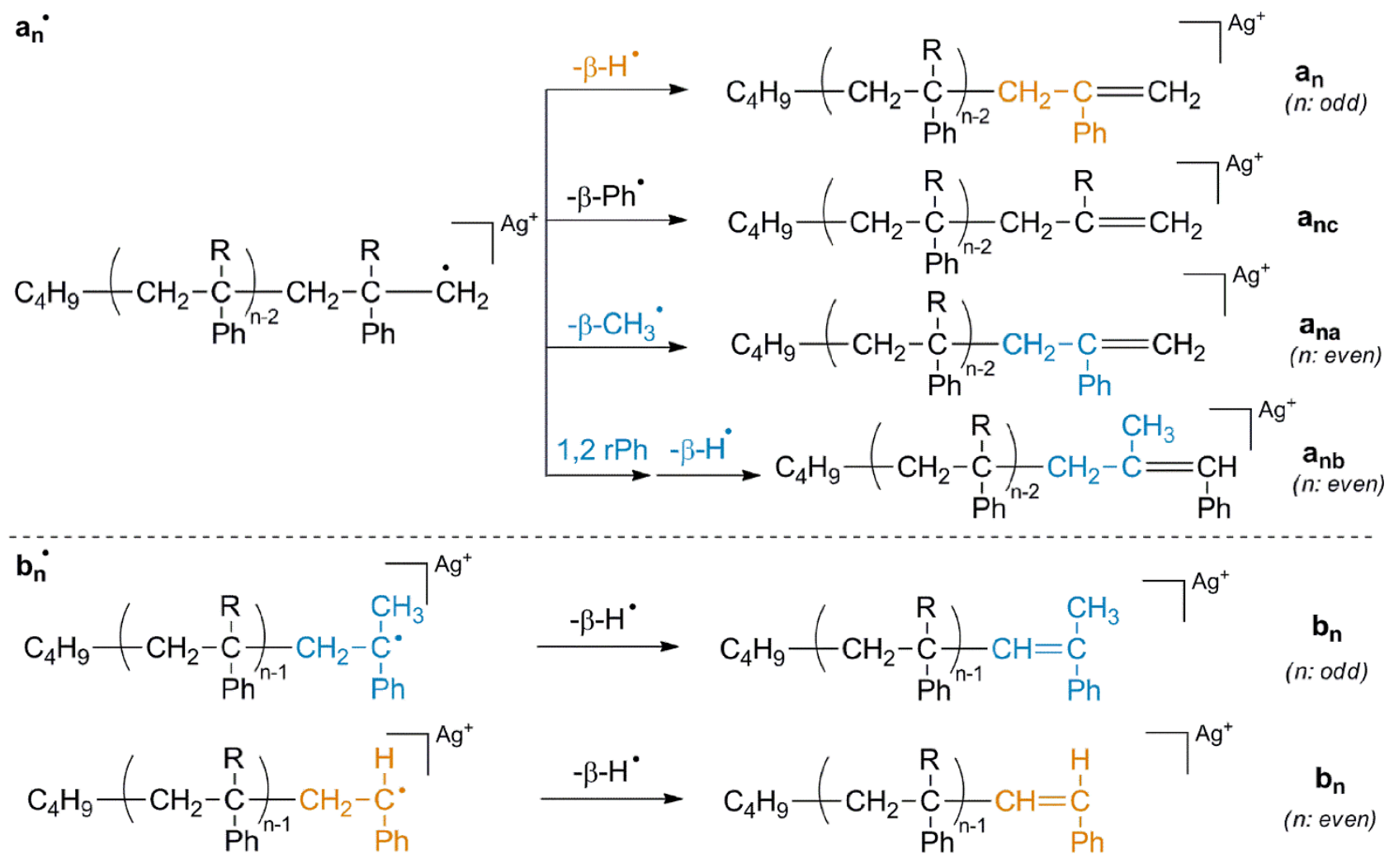

$z_{n}$
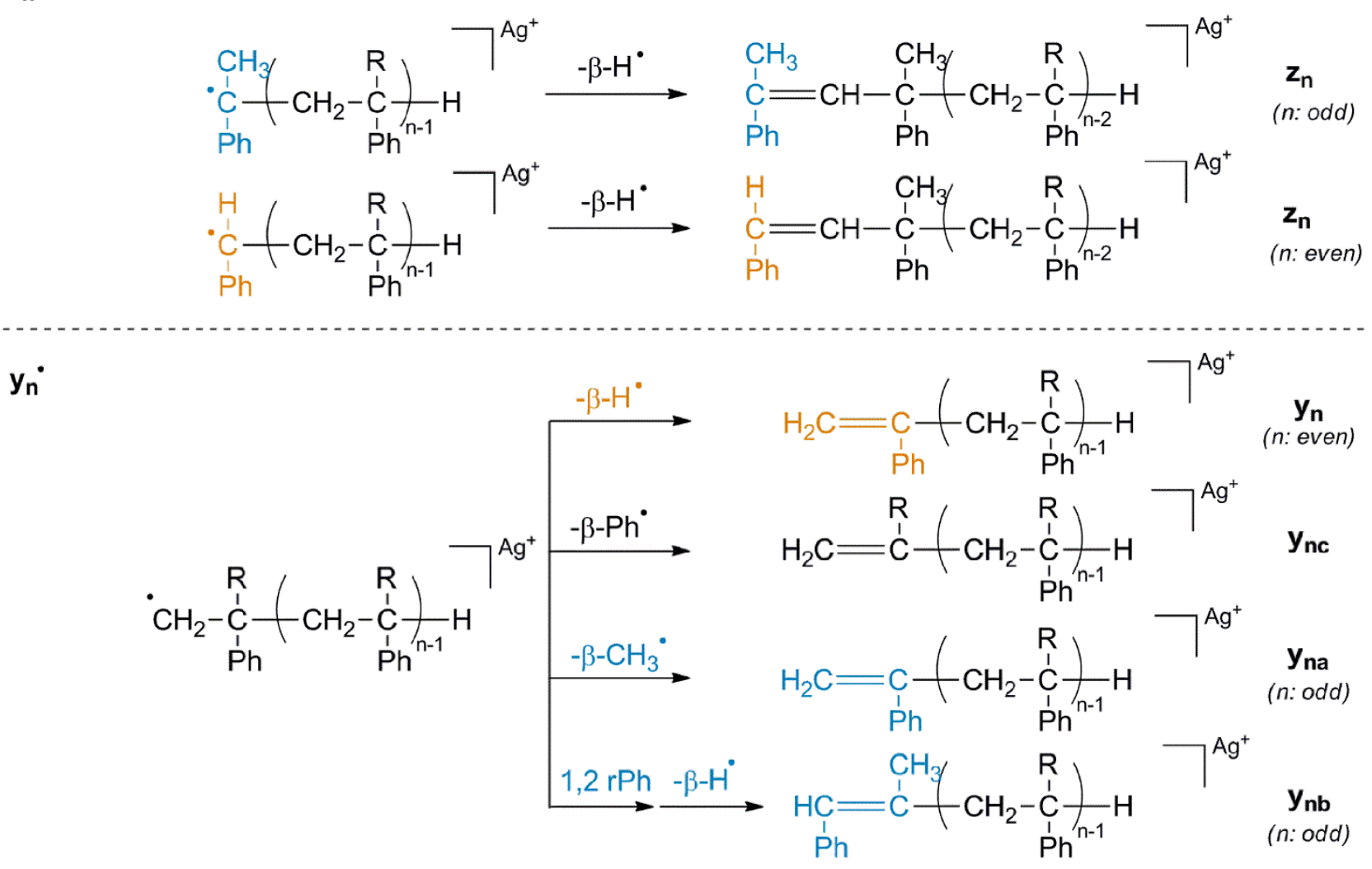

Figure S3: Primary $\left(\mathrm{a}_{\mathrm{n}} \bullet / \mathrm{y}_{\mathrm{n}}{ }^{\bullet}\right)$ and benzylic $\left(\mathrm{b}_{\mathrm{n}} \bullet / \mathrm{z}_{\mathrm{n}}{ }^{\bullet}\right)$ radical ions arising by random homolytic C-C bond cleavage in MSt-co-St and their derivative fragments resulting from consecutive $\beta$ scissions. $\mathrm{R}=\mathrm{CH}_{3}$ for $\alpha$-methylstyrene and $\mathrm{R}=\mathrm{H}$ for styrene monomeric units. Detailed fragment structures drawn for the 13-mer analysis. 


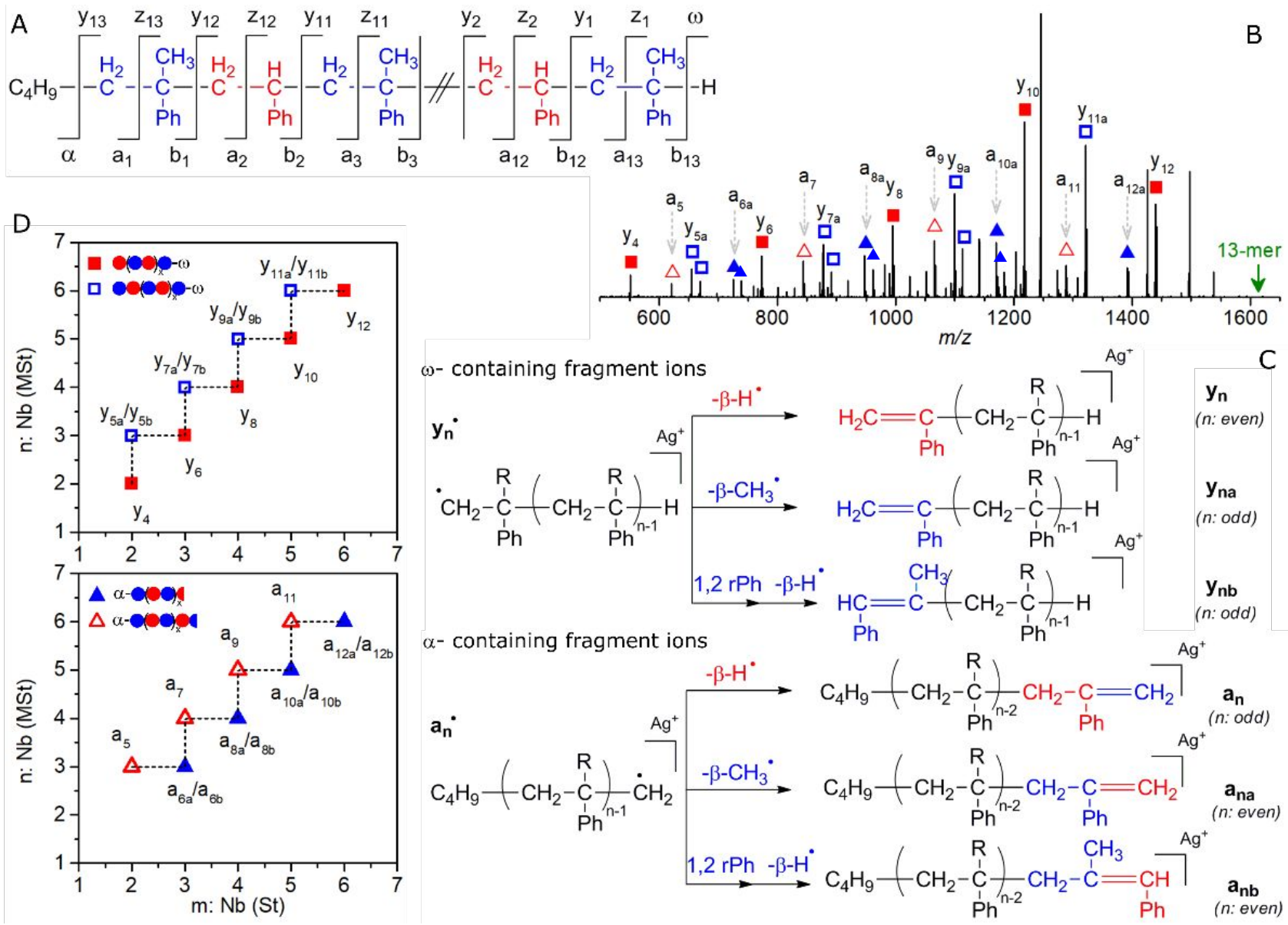

Figure $\mathrm{S}_{4}$. Summary of the MS² data interpretation for poly(MSt-alt-St) 2 13-mers. (A) Dissociation scheme and nomenclature for the $\mathrm{MS}^{2}$-CID fragmentation of poly(MSt-alt-St) 13-mers with defined terminal groups $\left(\alpha: \mathrm{C}_{4} \mathrm{H}_{9}, \omega: \mathrm{H}\right)$. (B) ESI-HR-MS² spectrum of poly(MSt-alt-St) 2 silver cationized 13-mer molecule with $\mathrm{m} / \mathrm{z}=1615.91$ and the proposed fragment assignment. (C) Primary radical ions $\mathrm{y}_{\mathrm{n}^{\bullet}}$ arising by random homolytic $\mathrm{C}-\mathrm{C}$ bond cleavage in poly(MSt-alt-St) 13-mers and their derivative fragments resulting from consecutive $\beta$ scissions. $\mathrm{R}=\mathrm{CH}_{3}$ for MSt and $\mathrm{R}=\mathrm{H}$ for St. (D) Composition of product fragment ions based on the assignment model.

A

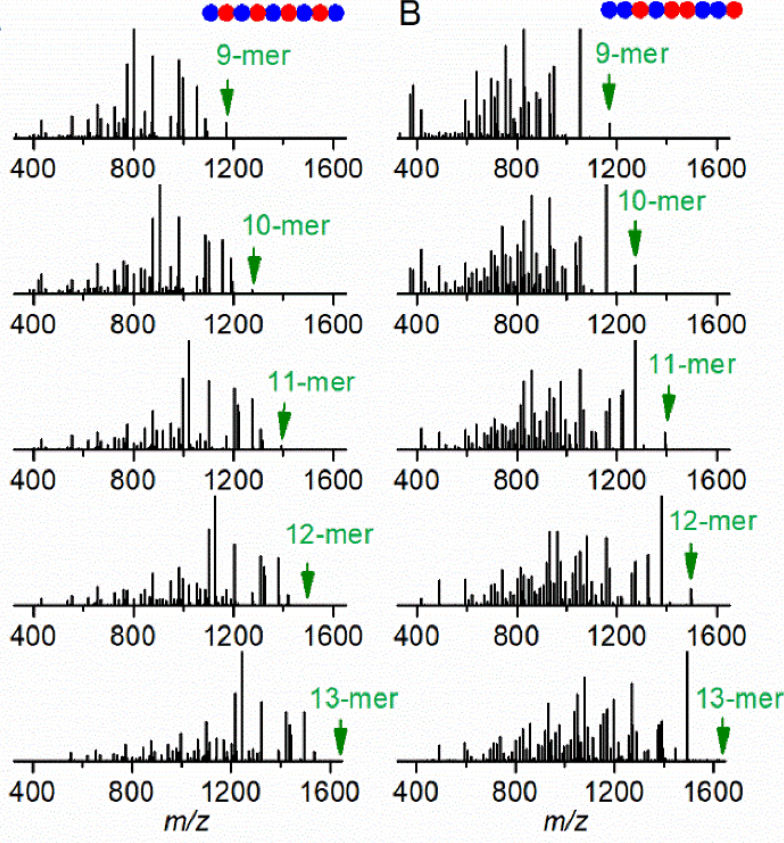

Figure S5: ESI-HR-MS² spectra of (A) poly(MSt-alt-St) 2 and (B) poly(MSt-random-St) (at CID Elab $=40$ ) obtained from the following precursor ions: 9-mer $\left[\mathrm{C}_{4} \mathrm{H}_{9}-\left(\mathrm{C}_{8} \mathrm{H}_{8}\right)_{4}\left(\mathrm{C}_{9} \mathrm{H}_{10}\right)_{5}-\mathrm{H}+\mathrm{Ag}\right]^{+}$ with $\mathrm{m} / \mathrm{z}=1171.62 ; 10-\mathrm{mer}\left[\mathrm{C}_{4} \mathrm{H}_{9}-\left(\mathrm{C}_{8} \mathrm{H}_{8}\right)_{5}\left(\mathrm{C}_{9} \mathrm{H}_{10}\right)_{5}-\mathrm{H}+\mathrm{Ag}\right]^{+}$with $\mathrm{m} / \mathrm{z}$ $=1275.69$; 11-mer $\left[\mathrm{C}_{4} \mathrm{H}_{9}-\left(\mathrm{C}_{8} \mathrm{H}_{8}\right)_{5}\left(\mathrm{C}_{9} \mathrm{H}_{10}\right)_{6}-\mathrm{H}+\mathrm{Ag}\right]^{+}$with $\mathrm{m} / \mathrm{z}=$ 1393.77; 12-mer $\left[\mathrm{C}_{4} \mathrm{H}_{9}-\left(\mathrm{C}_{8} \mathrm{H}_{8}\right)_{6}\left(\mathrm{C}_{9} \mathrm{H}_{10}\right)_{6}-\mathrm{H}+\mathrm{Ag}\right]^{+}$with $\mathrm{m} / \mathrm{z}=1497.83$ and 13-mer $\left[\mathrm{C}_{4} \mathrm{H}_{9}-\left(\mathrm{C}_{8} \mathrm{H}_{8}\right)_{6}\left(\mathrm{C}_{9} \mathrm{H}_{10}\right)_{7}-\mathrm{H}+\mathrm{Ag}\right]^{+}$with $\mathrm{m} / \mathrm{z}=1615.91$. The arrow indicates the selected precursor ion $\mathrm{m} / \mathrm{z}$. 